\title{
PERSEPSI GENERASI MUDA (PEMUDA) TERHADAP KEGIATAN PERTANIAN PADA USAHA TANI PADI SAWAH DI KELURAHAN LALEBATA KECAMATAN PANCA RIJANG KABUPATEN SIDENRENG RAPPANG
}

\author{
Oleh \\ Ibrahim $^{1}$, Irmayani' ${ }^{2}$ A.Erna Sriwahyuingsih ${ }^{3}$ \\ Email : ibrahim.budi95@gmail.com, : irmaumpar@yahoo.co.id \\ Program Studi Agribisnis. Fakultas Pertanian, Peternakan dan Perikanan \\ Universitas Muhammadiyah Parepare
}

\begin{abstract}
This study aims to examine the perceptions of the younger generation (youth) on agricultural activities in lowland rice farming in Lalebata Village, Panca Rijang District, Sidrap Regency. This research was conducted from September to November. Data collection techniques used in this study are observation, interview and questionnaire techniques. and data sources used are primary and secondary data. The data analysis used in this research is descriptive statistics and Likert scale. The results showed that the perception of the younger generation (youth) on the income indicator obtained a value of 356 in (medium category) because the income they earn in lowland rice farming is sometimes unstable, on the role indicator is it obtained a value of 507 in (high category), lowland rice farming in Lalebata village as a source of incomel development and job satisfaction indicators obtained a value off 244 (low category) their perception of job satisfaction is classified as agree if the rice farming business is very heavy and performing.
\end{abstract}

Keywords: Perception, Young Generation, Agriculture, Paddy Rice Farming.

ABSTRAK

Penelitian ini bertujuan untuk mengkaji persepsi generasi muda (pemuda) terhadap kegiatan pertanian pada usaha tani padi sawah di Kelurahan Lalebata Kecamatan Panca Rijang Kabupaten Sidrap penelitian ini dilaksanakan pada bulan september sampai november. Teknik pengumpulan data yang digunakan pada penelitian ini yaitu teknik observasi, wawancara dan kuisioner dan sumber data digunakan yaitu data primer dan sekunder. Analisis data yang digunakan pada penelitian ini adalah statistik deskriptif dan skala likert. Hasil penelitian menunjukkan bahwa persepsi dari generasi muda (pemuda) pada indikator pendapatan di peroleh nilai 356 berada pada (kategori sedang) dikarenakan pendapatan yang mereka peroleh pada usaha tani padi sawah terkadang tidak stabil, pada indikator peranan di peroleh nilai 507 berada pada (kategori tinggi) dikarenakan peranan usahatani padi sawah di Kelurahan Lalebata sebagai sumber dari pemasukan dan pembangunan dan indikator kepuasan kerja di peroleh nilai 244 berada pada (kategori rendah) persepsi mereka terhadap kepuasan kerja tergolong setuju jika usaha tani padi sawah itu sangat berat dan melelahkan.

Kata Kunci: Persepsi, Generasi Muda, Pertanian, Usaha Tani Padi Sawah.

\section{A. PENDAHULUAN}

Sektor pertanian merupakan sektor yang sangat berperan penting dalam pembangunan ekonomi Indonesia, dari ke empat sektor produksi yaitu pertanian, perindustrian, pertambangan dan 
perdagangan (jasa), yang jumlahnya 100 persen pada setiap tahun, maka peran sektor pertanian dalam PDB pada tahun 2018 adalah naik sekitar 47 persen di banding pada tahun 2013 - 2017 Hanya sekitar 27 persen. sedangkan peran atau kontribusi ke tiga sektor lainnya hanya 39 persen (Tarigan 2006). Selain itu, Mukhyi (2007) turut menambahkan "pertanian juga mempunyai kontribusi yang besar terhadap peningkatan devisa, yaitu lewat peningkatan ekspor dan atau pengurangan tingkat ketergantungan negara terhadap impor atas komoditi pertanian”. Pada fase awal pembangunan ekonominya, penduduk Indonesia juga banyak menggantungkan pendapatan hidupnya pada sektor pertanian dan sebagian besar tenaga kerja Indonesia bekerja di sektor pertanian karena sektor pertanian berkontribusi dalam penyerapan tenaga kerja dan tidak diperlukan keterampilan yang tinggi untuk mengerjakannya.

Pertanian adalah pemanfaatan sumber daya yang dilakukan manusia untuk menghasilkan bahan pangan. Kegiatan pemanfaatan sumber daya hayati yang termasuk dalam pertanian biasa dipahami orang sebagai budidaya tanaman. Pertanian adalah hal yang substansial dalam pembagunan, yaitu sebagai pemenuhan kebutuhan pangan, penyedia bahan mentah untuk industri, penyedia lapangan kerja, dan penyumbang devisa negara.

Sektor pertanian dalam kaitannya dengan sektor yang penting dalam pembagunan tidak terhindar dari masalah, terdapat pergeseran kesempatan kerja di lahan pertanian. Dapat di lihat bahwa pekerja di sektor pertanian rata-rata berusia tua sedangkan tenaga kerja untuk yang berusia muda mulai jarang didapati bekerja di lahanpertanian (Anonim, 2009).

Pekerjaan di lahan pertanian sudah mulai berkurang sejak kurangnya minat generasi muda untuk bergabung atau bekerja sebagai petani, sehingga tidak jarang terlihat bahwa para petani sekarang lebih banyak melibatkan teknologi untuk mengelolah lahan. Sebagai lahan pertanian terbesar di dunia, indonesia dengan sumber daya alam yang bermacam macam. Jika dilihat dari pekerjaannya maka jelas terlibat bahwa pekerjaan di bidang pertanian sebagian besar adalah orang tua. Generasi muda yang termasuk kedalam tenaga kerja sedikit, karena generasi muda memiliki persepsi tersendiri terhadap pekerjaan pertanian. Generasi muda merupakan salah satu aset bangsa yang memiliki 
sebagai penentu keberhasilan pelaksanaan kegiatan pertanian (Anonim, 2009).

Oleh karena itu, usia remaja juga termasuk dalam usia angkatan kerja. Di beberapa daerah, terutama di pedesaan, anak usia remaja bahkan sudah dijadikan pekerja untuk menambah penghasilan orang tuanya, termasuk membantu dengan menjadi tenaga kerja di sektor pertanian. Sebelum mereka menentukan untuk memilih jenis pekerjaan yang akan mereka tekuni, mereka terlebih dahulu mempunyai suatu pandangan mengenai jenis pekerjaan tersebut.

Menurut Undang-undang No. 25 tahun 1997, tenaga kerja didefinisikan sebagai penduduk berusia 15 tahun atau lebih. Tenaga kerja (man power) adalah penduduk pada usia kerja berumur 15-64 tahun (menurut sensus penduduk tahun 1971).

Peneliti ingin melihat apakah generasi muda (pemuda) di Kelurahan Lalebata ini akan bertani sesuai dengan pemahaman mereka terhadap kegiatan pertanian usaha tani padi sawah. Oleh karena itu, Kelurahan Lalebata menarik untuk diteliti persepsi generasi mudanya (pemuda) terhadap pekerjaan di usaha tani pertanian padi sawah, karena banyak generasi muda (pemuda) yang tidak terlibat langsung dalam kegiatan pertanian, terlebih generasi muda (pemuda) yang lebih cepat terpengaruh terhadap perkembangan zaman yang sekarang sudah memasuki industri 4.0 yang dimana segala sesuatu sudah bersentuhan dengan terknologi, dan itu sangat berdampak terhadap kegiatan pertanian, dalam hal ini sektor pertanian lebih di fokuskan pada tanaman padi sawah.

\section{B. METODE PENELITIAN}

Penelitian ini dilakukan pada bulan September-November tahun 2020, peneliti mengambil lokasi di Kelurahan Lalebata, Kecamatan Pancarijang, Kabupaten Sidenreng Rappang, dengan pertimbangan melihat kurangnya minat generasi muda di Kelurahan Lalebata terhadap kegiatan usaha tani padi sawah.

Populasi dalam penelitian ini adalah pemuda yang ada di Kelurahan Lalebata, Kecamatan Panca rijang, Kabupaten Sidenreng Rappang yang berjumlah 340 tahun 2020, melihat jumlah populasi yang cukup besar yaitu 340 orang pemuda maka dilakukan pengambilan sampel menggunakan rumus slovin (Putra, 2000):

$n=\frac{N}{1+N(e)^{2}}$

Dimana :

$\mathrm{n}$ = Jumlah Sampel

$\mathrm{N}=$ Jumlah Populasi

$\mathrm{e}=$ Tingkat Kelonggoran $(15 \%)$

Sehingga sampel yang diambil sebanyak 44 responden. 
Jenis dan sumber data yang digunakan pada penelitian ini yaitu data primer dan data sekunder.Teknik pengumpulan data yang digunakan pada penelitian ini yaitu teknik observasi, teknik wawancara dan teknik angket/ kuisioner.Analisis data yang digunakan dalam penelitian ini adalah Skala likert, kemudian hasil penelitian tersebut juga menggunakan analisis deskriptif. Instrumen yang digunakan dalam penelitian ini adalah lembar angket yang berisi beberapa pertanyan dengan tiga indikator yakni indikator pendapatan, peranan dan kepuasan kerja. Desain pengukuran yang digunakan adalah skala likert dengan lima bagian skala, yaitu: sangat setuju, setuju, cukup setuju, tidak setuju, dan sangat tidak setuju. Untuk pengukuran setiap sub variabel penelitian dapat di kemukakan sebagai berikut :

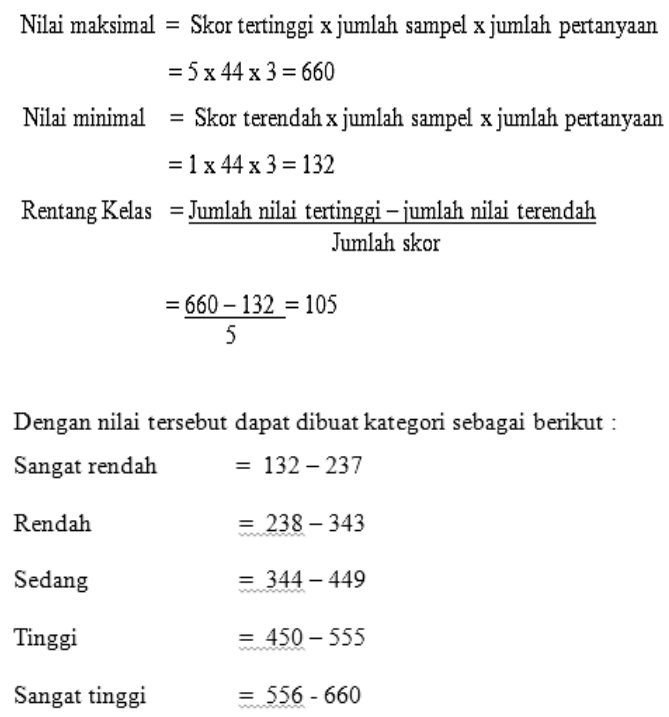

\section{HASIL DAN PEMBAHASAN}

Setelah dilakukan pengumpulan data dan analisis data, hasil deskripsi dikelompokkan data skor persepsi dengan tiga indikator, yakni indikator pendapatan, peranan dan kepuasan kerja sebagai berikut:

Tabel 1. Penilaian Persepsi Generasi Muda (Pemuda) tentang Pendapatan Usaha Tani Padi Sawah di Kelurahan Lalebata Kecamatan Panca Rijang Kabupaten SIDRAP

\begin{tabular}{clc}
\hline No. & \multicolumn{1}{c}{ Indikator } & $\begin{array}{c}\text { Skor } \\
\text { Akhir }\end{array}$ \\
\hline 1. & Bekerja sebagai petani dapat memenuhi kebutuhan sehari-hari & $\mathbf{1 2 2}$ \\
\hline 2. & $\begin{array}{l}\text { Bekerja sebagai petani dapat menghasilkan uang yang cukup } \\
\text { untuk biaya sekolah }\end{array}$ & $\mathbf{1 0 8}$ \\
\hline 3. & $\begin{array}{l}\text { Bekerja sebagai petani dapat mengahasilkan uang untuk } \\
\text { ditabung }\end{array}$ & $\mathbf{1 2 6}$ \\
\hline & Total & $\mathbf{3 5 6}$ \\
\hline
\end{tabular}

Sumber: Data Primer Setelah Diolah, 2020 
Berdasarkan data pada Tabel 1 dapat di jelaskan bahwa terdapat tiga indikator pertanyaan. Hasil penjumlahan dari indikator pertama pendapatan yaitu bekerja sebagai petani dapat memenuhi kebutuhan sehari-hari maka diperoleh skor akhir 122. Indikator kedua yaitu bekerja sebagai petani dapat menghasilkan uang yang cukup untuk biaya sekolah, adapun skor akhir yang diperoleh adalah 108. Indikator ketiga yaitu bekerja sebagai petani dapat menghasilkan uang yang cukup untuk di tabung, adapun skor akhir yang diperoleh adalah 126.

Berdasarkan Tabel 1, pada penelitian Muksin (2007) mengemukakan bahwa pemuda memiliki persepsi mengolah lahan atau sumber daya lain dinilai belum menjadi kegiatan yang produktif dan tidak akan banyak menghasilkan uang. Persepsi semacam ini dipengaruhi oleh teman teman sebaya yang sudah bekerja di kota.

Tabel 2. Penilaian Persepsi Generasi Muda (Pemuda) tentang Peranan di Kelurahan Lalebata Kecamatan Pancarijang Kabupaten SIDRAP

\begin{tabular}{|c|c|c|}
\hline No. & Indikator & $\begin{array}{c}\text { Jumlah } \\
\text { Bobot }\end{array}$ \\
\hline 1. & $\begin{array}{c}\text { Usahatani padi sawah merupakan sumber pemasukan } \\
\text { pembangunan/pendapatan }\end{array}$ & 133 \\
\hline 2. & Keperluan diri sendiri & 163 \\
\hline \multirow[t]{2}{*}{3.} & Memenuhi kebutuhan pasar & 211 \\
\hline & Total & 507 \\
\hline
\end{tabular}

Sumber: Data Primer Setelah Diolah, 2020

Berdasarkan data pada Tabel 2 memenuhi kebutuhan pasar maka skor dapat dijelaskan bahwa terdapat tiga indikator pertanyaan. Hasil penjumlahan dari indikator pertama yaitu usaha tani akhir yang diperoleh adalah 211.

padi sawah merupakan sumber Berdasarkan Tabel 2, menurut latifah (2007) menjelaskan proses pemasukan pembagunan/pendapatan terjadinya persepsi yang dimulai dari maka di peroleh skor akhir adalah 133. objek yang menimbulkan stimulus Indikator kedua yaitu keperluan diri kemudian stimulus yang mengenai alat sendiri maka skor akhir yang diperoleh indera diteruskan oleh syaraf sensoris ke otak dan terjadilah proses pengamatan adalah 163. Indikator ketiga yaitu yang di pengaruhi oleh faktor 
pengalaman, proses belajar, cakrawalah tersebut.

dan pengetahuan yang dimiliki oleh orang

Tabel 3. Penilaian persepsi generasi muda (Pemuda) tentang Kepuasan Kerja di Kelurahan Lalebata Kecamatan Pancarijang Kabupaten SIDRAP

\begin{tabular}{|c|c|c|}
\hline No. & Indikator & $\begin{array}{c}\text { Jumlah } \\
\text { Bobot }\end{array}$ \\
\hline 1. & $\begin{array}{c}\text { Jam kerja sebagai petani lebih panjang/banyak dari jam kerja } \\
\text { yang bekerja di luar pertanian }\end{array}$ & 81 \\
\hline 2. & $\begin{array}{c}\text { Bekerja sebagai petani berarti pekerjaan yang berat dan } \\
\text { melelahkan }\end{array}$ & 104 \\
\hline \multirow[t]{2}{*}{3.} & Bekerja sebagai petani akan merusak fisik/penampilan & 59 \\
\hline & Total & 244 \\
\hline
\end{tabular}

Sumber: Data Primer Setelah Diolah, 2020

Berdasarkan data pada Tabel 3 terlibat dengan sesuatu kegiatan karena dapat dijelaskan bahwa terdapat tiga menyadari pentingnya atau bernilainya indikator pertanyaan. Hasil penjumlahan kegiatan tersebut, dari beberapa uraian di dari indikator pertama yaitu jam kerja sebagai petani lebih panjang/banyak dari jam kerja yang bekerja di luar pertanian maka skor akhir yang diperoleh adalah 81. Indikator kedua yaitu bekerja sebagai petani berarti pekerjaan berat dan melelahkan maka skor akhir yang diperoleh adalah 104. Indikator ketiga yaitu bekerja sebagai petani merusak fisik/penampilan skor akhir yang diperoleh adalah 59.

Berdasarkan Tabel 3, menurut atas, secara umum dapat di ambil kesimpulan bahwa kepuasan kerja terhadap kegiatan pertanian merupakan suatu sikap ketertarikan pemuda terhadap kegiatan pertanian atas dasar kepuasan kerja sebagai petani.

Berdasarkan hasil penelitian yang telah diuraikan, mengenai persepsi generasi muda (pemuda) terhadap kegiatan pertanian pada usaha tani padi sawah di Kelurahan Lalebata Kecamatan Pancarijang Kabupaten Sidenreng Sarwono, (2010) minat merupakan bentuk Rappang, rekapitulasinya dapat dilihat sikap ketertarikan dalam atau sepenuhnya pada Tabel 4.

Tabel 4. Hasil Rekapitulasi Persepsi Generasi Muda (Pemuda) Kegiatan Usaha Tani Padi sawah

\begin{tabular}{|c|c|c|c|}
\hline Variabel & Sub variabel & Nilai & Keterangan \\
\hline \multirow{2}{*}{$\begin{array}{c}\text { Persepsi Generasi } \\
\text { Muda (Pemuda) }\end{array}$} & Pendapatan & 356 & Kategori Sedang \\
\cline { 2 - 4 } & Peranan & 507 & Kategori Tinggi \\
\cline { 2 - 4 } & Kepuasan Kerja & 244 & Kategori Rendah \\
\hline
\end{tabular}


Berdasarkan Tabel 4 total bahwa para pemuda setuju jika usaha tani keseluruhan dari tiga sub yakni 1107. padi sawah itu berarti melakukan kegiatan Penilaian tersebut meliputi tiga sub seperti pengolahan tanah, pemupukan, variabel yaitu, pendapatan dengan total penanaman, sampai dengan pemanenan, 356, peranan dengan total 507, dan yang bertempat ruang terbuka dan terkena kepuasan Kerja dengan total 244.

Tabel 4 menunjukkan bahwa total nilai yang diperoleh dari sub variabel pendapatan adalah 356 dengan interval (344 - 449), yang berada pada kategori sedang. Nilai yang diperoleh dari sub variabel peranan adalah 507 dengan interval (450 - 555) yang berada pada kategori tinggi. Nilai yang diperoleh dari sub variabel kepuasan kerja adalah 244 dengan interval $(238$ - 343) yang berada pada kategori rendah.

Berdasarkan data diatas untuk variabel pendapatan menunjukkan kategori sedang, jika pendapatan pada usaha tani itu terkadang cukup dan terkadang tidak mencukupi apalagi kebutuhan sehari - hari, biaya sekolah dan untuk di tabung, untuk variabel peranan menunjukkan kategori tinggi, disebabkan karena sebagian pemuda memiliki peran di usaha tani padi sawah, serta peranan usaha tani padi sawah sebagai sumber pemasukan dan pembangunan, untuk variabel kepuasan kerja menurut persepsi generasi pemuda (pemuda) menunjukkan kategori rendah, matahari langsung, berarti kegiatan usaha tani padi sawah juga melakukan kegiatan yang kotor dan berlumpur serta melelahkan dan bisa merusak fisik dan penampilan.

Menurut persepsi generasi muda (pemuda) kegiatan usaha tani padi sawah itu mereka memiliki berbagai perbedaan dari sisi pengetahuan dan keterampilan, dari hasil ini para pemuda memiliki tingkat pengetahuan dan keterampilan yang berbeda beda, apalagi di tinjau dari persepsi mereka sendiri, jika di tinjau Kelurahan Lalebata memiliki Pemuda yang produktif, tetapi banyak dari pemuda tersebut sudah tidak memiliki minat di usaha tani padi sawah.

\section{KESIMPULAN}

Berdasarkan hasil penelitian yang telah dilakukan, maka dapat ditarik kesimpulan hasil penelitian menunjukkan bahwa persepsi dari generasi muda (pemuda) sebagian besar pemuda mempunyai persepsi yang berbeda dalam hal pendapatan pada pekerjaan di sektor pertanian padi sawah disebabkan menurut persepsi mereka pendapatan usaha tani itu 
terkadang tidak menentu dan juga masa depan tidak terjamin.

Persepsi dari indikator peranan sektor pertanian dalam hal ini menjadi sumber pendapatan bagi penduduk yang hidup di Kelurahan Lalebata, dan dapat menghasilkan produk yang dapat memenuhi kebutuhan pangan sendiri (subsistence) maupun kebutuhan pasar di luar desa, ini merupakan bahan pertimbangan yang membentuk persepsi yang positif di kalangan pemuda. Persepsi pada indikator kepuasan kerja di sektor pertanian sebagian besar pemuda di Kelurahan Lalebata mempunyai persepsi yang berbeda, salah satunya menurut mereka, usaha tani padi sawah yakni bekerja di ruang terbuka dan terkena matahari langsung serta melakukan pekerjaan yang kotor, berlumpur dan melelahkan.

\section{DAFTAR PUSTAKA}

Agustina D. 2011. Persepsi dan Motivasi Berperan Serta dalam Program Pos Pemberdayaan Keluarga (Posdaya) (Kasus: Peserta Posdaya Mandiri Terpadu di RW 01, Desa Cikarawang, Kecamatan Dramaga, Kabupaten Bogor) [skripsi]. Bogor (ID): Institut Pertanian Bogor.

Ahmadi A, Sholeh M. 2005. Psikologi Perkembangan. Jakarta (ID): PT Rineka Cipta.

Astuti M, Siswati, Setyawan I. 2007. Hubungan Antara Persepsi Terhadap Pembelajaran Kontekstual Dengan Minat Belajar
Matematika Pada Siswa Kelas VII SMP Negeri 18 Semarang. [Internet]. [10:15]. [diunduh 2011 Februari 14] Tersedia pada: http://eprints.undip .ac.id/24784/1/JURNAL_MUJI_A_ _M2A605053_.pdf.

[BPS] Badan Pusat Statistik. 2013. Berita Resmi Statistik. Hasil Sensus Pertanian $2013 \quad$ (Angka Sementara). Jakarta (ID): Badan Pusat Statistik Indonesia.

Calhoun JF, Acocella JR. 1995. Psikologi Tentang Penyesuaian dan Hubungan Kemanusiaan. Semarang (ID): IKIP Semarang Press.

Chandra D. 2004. Persepsi Pemuda Desa Terhadap Pekerjaan Di Sektor Pertanian dan Minat Bekerja Di Kota [skripsi]. Bogor (ID): Institut Pertanian Bogor.

Daniel. A. 2004.ProduktivitasKerja.http:// danielspot.blogspot.com/2004/06/pr oduktivitas-kerja.html

Daulay P. 2006. Sekali Buruh Tetap Buruh: Studi Pembentukan Generasi Buruh di Perkebunan Tembakau Deli, Kabupaten Deli Serdang, Sumatera Utara. [disertasi].

Bogor (ID): Institut Pertanian Bogor.

Faridah K. 2007. Dari Ekonomi Pertanian Ke Ekonomi Industri (Sejarah Kehidupan Sosial Ekonomi Masyarakat Kubangwungu Kecamatan Ketanggungan Kabupaten Brebes Tahun 19692000). [skripsi].[Internet].[10:15]. [diunduh 2011 Januari 3]. Tersedia pada:

http://digilib.unnes.ac.id/gsdl/collect /skripsi/archives/HASHe11f. dir/doc.pdf

Ilham N, Suradisastra K, Pranadji T, Agustian A, Hardono GS, Hastuti EL. 2007. Analisis Profil Petani dan Pertanian Indonesia. Makalah Seminar Hasil 
Penelitian. [Internet]. [13:17]. [diunduh 2010 Desember 30].Tersedia pada: http://pse.litbang.deptan.go.id/ind/p dffiles/SHP_NYK_2007.pdf

Pratomo S. 2010. Analisis Peran Sektor Pertanian Sebagai Sektor Unggulan di Kabupaten Boyolali Tahun 1998 - 2008.

Putra. W. 2012. Menentukan Jumlah Sampel dengan Rumus. http://analisis - statistik.

Blogspot.co./2012/09/menentukanjumlah-sampel-dengan- rumus .html.

Reza F. 2007. Sikap Petani Terhadap Pengendalian Hama Terpadu (Kasus di Kelurahan Balumbang jaya, Kecamatan Bogor Barat, Kota Bogor).

Sumber Daya dalam Sektor Pertanian [laporan penelitian]. Malang (ID): Universitas Brawijaya.

Yulianto. 1997. Faktor yang mempengaruhi perilaku bekerja pemuda anak tani di pedesaan. [skripsi]. (ID):IPB. Bogor. 